\title{
Desain Interior Kereta Api Eksekutif Plus dengan Menerapkan Tema Interior Clean Design
}

\author{
Jajang Wicaksono dan Andhika Estiyono \\ Departemen Desain Produk Industri, Fakultas Teknik Sipil dan Perencanaan, Institut Teknologi \\ Sepuluh Nopember (ITS) \\ e-mail: andhika@prodes.its.ac.id, jajangwicaksono00@gmail.com
}

\begin{abstract}
Abstrak - Realisasi peningkatan standarisasi kelas kereta api di Indonesia sudah mulai berjalan. Salah satu kelas yang sudah mengalami peningkatan standarisasi adalah kelas ekonomi menjadi ekonomi plus. Peningkatan standarisasi dilakukan dengan mereduksi jumlah penumpang dalam satu kereta dari 106 menjadi 80 kursi. Dalam jangka panjang nantinya semua kelas kereta api di Indonesia akan mengalami peningkatan standarisasi, tidak terkecuali dengan kelas eksekutif menjadi eksekutif plus. Aspek kenyamanan, keselamatan, serta estetika merupakan fokus utama dalam konsep desain kereta eksekutif plus ini. Perancangan ditujukan sebagai sajian alternatif desain interior kereta api eksekutif plus yang baru. Konsep interior pesawat terbang akan dijadikan rolemodel dalam perancangan interior kereta api eksekutif plus. Gaya desain merujuk pada tren kereta modern, simpel, dan futuristik. Kehadiran kereta api kelas eksekutif plus yang baru diharapkan mampu meningkatkan antusiasme publik terhadap penggunaan transportasi massal untuk jarak jauh khususnya pada kereta api.
\end{abstract}

Kata Kunci-Desain Interior, Eksekutif Plus, Kereta Api.

\section{PENDAHULUAN}

$\mathrm{K}$ ERETA saat ini merupakan salah satu moda transportasi favorit di Indonesia. Tapi keberadaan kereta api masih kalah dengan pesawat, khususnya untuk rute perjalanan jarak jauh. Apalagi saat ini beberapa maskapai penerbangan sudah menerapkan sistem budget airlines. Budget airlines merupakan sistem yang membuat harga tiket pesawat jauh lebih murah dari harga aslinya. Dengan harga yang murah pesawat menjadi moda transportasi yang cukup kompetitif khususnya untuk perjalanan jarak jauh.

Dalam perkembangannya calon penumpang tidak selamanya menjadikan pesawat terbang sebagai pilihan utama mereka. Ada beberapa alasan yang mendasari hal tersebut. Misalnya untuk tiket pesawat budget airlines biasanya kenyamanannya dan privasi penumpang sangat kurang. Tentu dengan harga yang murah banyak fasilitas yang dianggap tidak terlalu penting dihilangkan ataupun dikurangi demi mengejar harga tiket yang murah. Selain itu, persebaran bandar udara juga tidak merata, biasanya hanya terdapat di kota-kota besar saja. Letak bandar udara pun biasanya berada di pinggiran kota karena harus memenuhi standar keamanan. Dan lagi untuk orang yang phobia ketinggian jelas akan memilih kereta dibandingkan dengan pesawat.

Akan tetapi saat ini kereta api di Indonesia belum menyediakan penewaran fasilitas istimewa yang bisa membuat calon penumpang pesawat tertarik untuk berpindah menggunakan kereta api. fasilitas-fasilitas tersebut misalnya kebutuhan akan privasi penumpang, saat ini kereta yang beroperasi di Indonesia masih kurang mengakomodasi privasi bagi para penumpangnya. Terutama bagi mereka para pekerja yang melakukan perjalanan bisnis, dimana memerlukan istirahat lebih selama perjalanan. Selain itu mereka juga bisa jadi selama di dalam kereta akan tetap bekerja dan tidak mau terganggu oleh orang lain selama bekerja. Kereta super eksekutif (selanjutnya disebut eksekutif plus) merupakan salah satu projek PT INKA (persero) yang pengerjaannya masih belum diketahui waktunya. Hal ini dikarenakan belum adanya ketertarikan pihak penyelenggara kereta api di Indonesia ( dalam hal ini PT KAI) untuk menggunakannya dalam waktu dekat ini. Walaupun seperti itu, sebenarnya kereta eksekutif plus ini mempunyai potensi yang bisa dimaksimalkan dan bisa menjadi salah satu pemasukan penting bagi PT KAI.

Kereta super eksekutif ini sendiri akan mengambil rute jarak jauh dengan rentang kurang lebih $1000 \mathrm{~km}$ yang melalui jalur utara dan jalur tengah. Kira-kira jalur yang akan dipilih adalah jalur yang memrluka waktu tempuh diatas 10 jam yang benarbenar membutuhkan istirahat selama diperjalanan.

\section{URAIAN PENELITIAN}

\section{A. Pengambilan Data}

Data primer pada riset ini didapat melalui observasi (shadowing) terhadap penumpang kereta api jarak menengah sancaka pagi dan sancaka sore tujuan Surabaya-Yogyakarta dan sebaliknya. Pengamatan ini berlangsung selama 4 kali naik kereta yang bertujuan mendalami kebiasaan(behaviour) dari para penumpang selama di dalam kereta. Selain itu juga dilakukan deep interview kepada Divisi bagian Desain dan Rekayasa Bagian Desain Interior dari PT. INKA. Data sekunder diperoleh melalui studi literatur internet dan buku buku terkait

\section{B. Subjek dan Objek Perancangan}

1. Subjek perancangan : berupa desain interior kereta api yang dioperasikan oleh PT KAI selaku penyelengara moda transportasi umum kereta api, beroperasi dengan rute Surabaya-jakarta \& Surabaya-bandung dan sebaliknya.

2. Objek perancangan : berupa bagian interior kereta meliputi optimalisasi konfigurasi tempat duduk, ceiling atap, panel dinding, lantai, dan komponen interior yang disesuaikan dengan aktifitas dan perilaku calon 
penumpang. Selain itu juga penerapan efek psikologi pada desain baru baik berupa bentuk, warna, suara, maupun bau.

\section{Tahap Studi dan Analisis}

1. Studi Analisis Calon Penumpang : Studi analisis ini ditujukan untuk mengetahui aktifitas apa saja yang dilakukan penumpang di dalam kereta. Selain itu juga untuk mengetahui kebiasaan penumpang ketika di dalam kereta, baik ketika sendiri maupun bersama orang lain (keluarga, teman, maupun orang asing). Metode yang digunakan adalah dengan cara pengamatan secara langsung (shadowing) di dalam kereta.

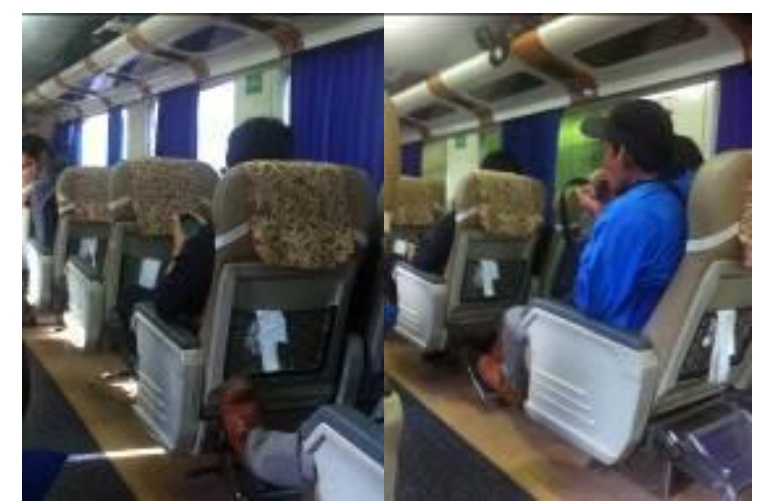

Gambar 1. Proses Shadowing.

2. Studi dan Analisis Positioning MSCA : Pada studi ini bertujuan untuk mengetahui posisi (kelebihankekurangan) kereta dibandingkan dengan moda transportasi publik lain yang beroperasi untuk perjalanan jarak jauh. Melalui analisis rute, kapasitas penumpang, fasilitas, dan kenyamanan maka akan didapatkan harga tiket dan psikografi calon pengguna. Kereta yang dijadikan sebagai subjek MSCA adalah Kereta Tanah Melayu, Eurostrar, China Bullet Train, Kereta Wisata (Imperial), dan Shinkansen Hayabusa.

3. Studi Analisis Ergonomi : Studi ini ditujukan untuk mengetahui dan mendapatkan batasan dimensi pada interior kereta, baik ketika penumpang diam maupun melakukan aktifitas. Batasan dimensi tersebut kemudian digunakan sebagai patokan untuk mengidentifikasi tingkat kenyamanan pengguna. Dikarenakan kereta ini nantinya merupakan produk mewah jadi tingkat kenyamanan pengguna di dalam kereta merupakan fokus utama perancangan. Fokus utama analisis ergonomi adalah kursi, gangway, dan bagasi.

4. Studi dan Analisis LOPAS : Bertujuan untuk memilih konfigurasi di dalam interior kereta. Studi ini dilakukan untuk mengidentifikasi sirkulasi penumpang di dalam kereta sehingga penumpang merasa nyaman ketika beraktifitas. Selain itu juga menentukan peletakan aksesoris di dalam kereta sehingga memudahkan penumpang menggunakannya.

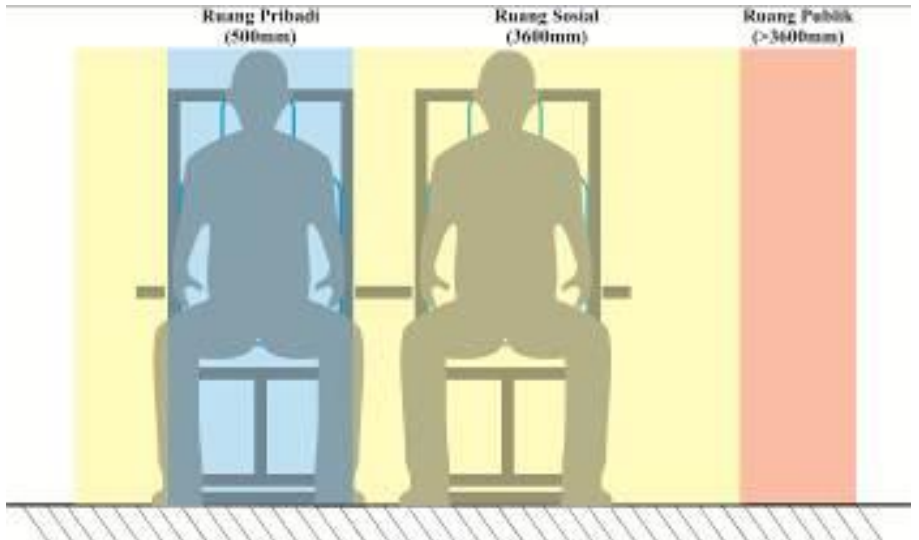

Gambar 2. Analisis Proksemik.

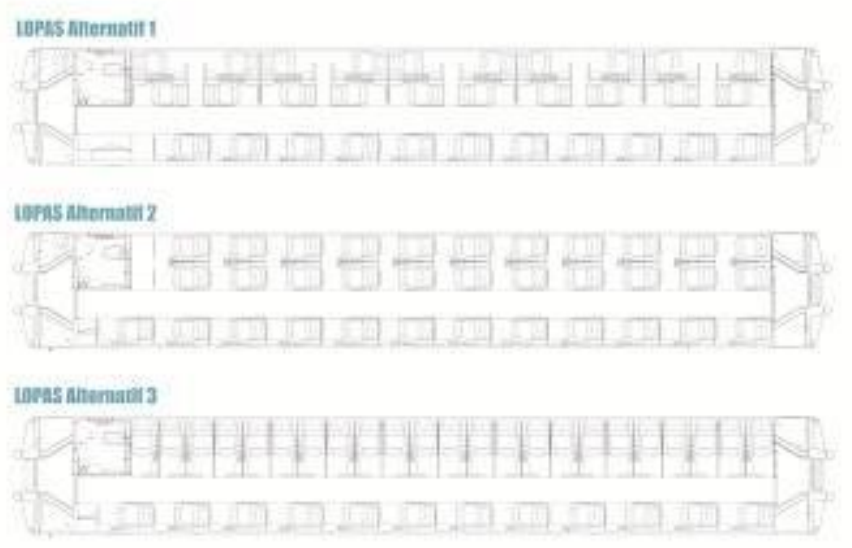

Gambar 3. Alternatif LOPAS.

5. Studi Analisis Trend Style : Studi ini ditujukan untuk mengidentifikasi trend style dari desain interior kereta yang telah berkembang saat ini. Trend desain yang di analisis tidak hanya dari desain interior saja, tetapi juga trend desain furniture dan produk. Yeng merupakan dua hal yang sangat dekat dengan pengembangan perancangan desain interior kereta ini.

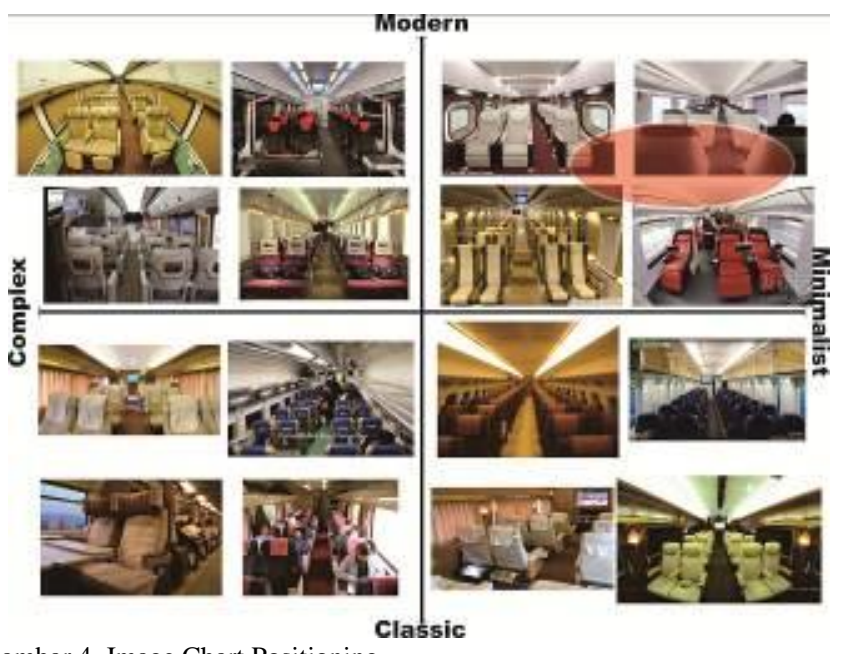

Gambar 4. Image Chart Positioning. 
6. Studi dan Analisis Detail Enginnering Design : Studi ini bertujuan untuk mengetahui detail komponen teknologi yang sesuai dengan konsep desain yang akan diterapkan pada desain nantinya. Sealin itu juga untuk mengetahui apakah teknologi tersebut cocok atau tidak untuk dipasang.

7. Analisis Tema Interior Clean Design : sesuai dengan judul, interior kereta ini menerapkan tema desain clean design. Analisis ini bertujuan untuk mengetahui bentuk yang akan diterapkan pada interior kereta agar sesuai dengan tema clean design tersebut.

\section{HASIL PENELITIAN}

\section{A. Penerapan Bentuk dan Estetika}

Tren desain yang didapatkan dari analisis di terapkan pada interior kereta api. dengan mengacu pada hasil analisis DED maupun ergonomi maka dibuatlah eksplorasi sketsa desain. Dari eksplorasi sketsa ini dipilih sketsa guna dipilih sebagai alternatif desain.

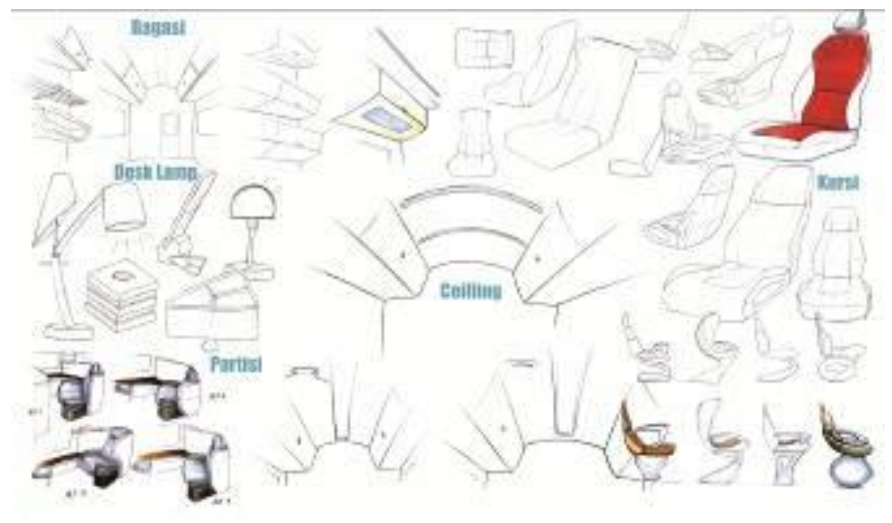

Gambar 5. Alternatif Desain.

Dari alternatif tersebut dipilihlah masing-masing satu desain yang akan diterapkan. Selain itu juga dilakukan pemilihan warna berdasarakan analisis tren desain sebelumya.

\section{B. Final Desain}

Setelah didapat desain yang diinginkan dilanjut dengan melakukan 3D modeling guna mengetahui bentuk 3 dimensi interior setelah desain diterapkan.

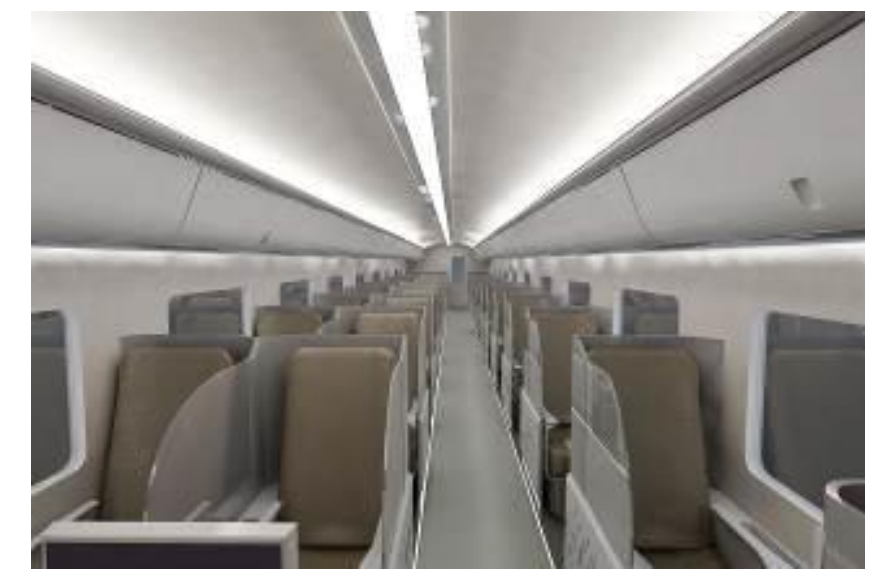

Gambar 6. Final Design 1.

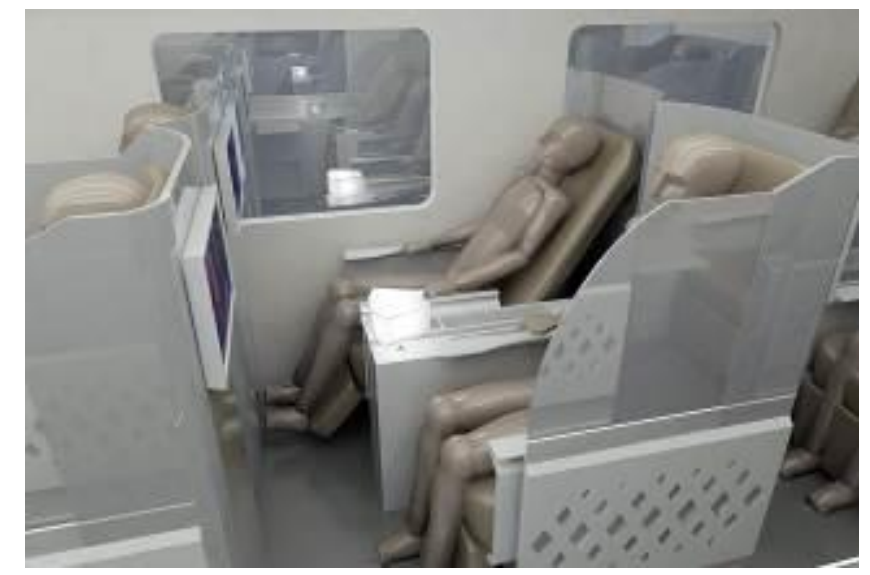

Gambar 7. Final Design 1.

\section{Studi Model Berskala}

Studi model dilakukan agar mengetahui impresi desain secara langsung.

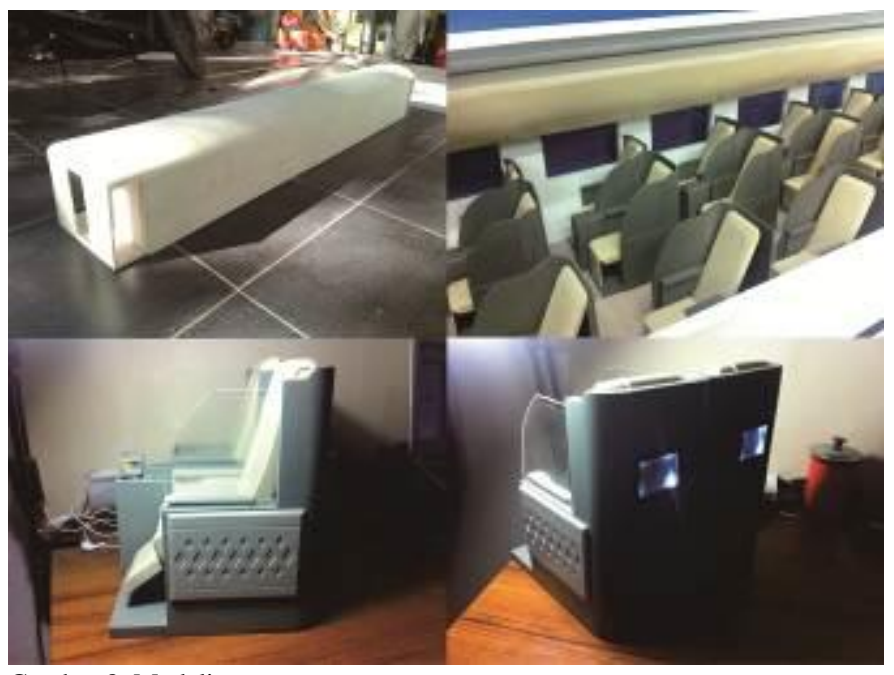

Gambar 8. Modeling.

\section{KESIMPULAN}

Penelitian ini bertujuan untuk meningkatkan kualitas kereta yang ada di Indonesia saat ini dengan cara membuat kelas baru dari pengembangan kelas eksekutif yang sudah ada. Berikut adalah kesimpulan yang didapat dari penelitian ini:

Tabel 1.

Kesimpulan Desain

\begin{tabular}{|c|c|c|}
\hline No. & Permasalahan & $\begin{array}{l}\text { Solusi } \\
\end{array}$ \\
\hline 1. & $\begin{array}{l}\text { PT KAI sebagai } \\
\text { penyelenggara perkereta } \\
\text { apian di Indonesia belum } \\
\text { memiliki kereta kelas } \\
\text { satu setara } \\
\text { eksekutif/diatasnya } \\
\text { untuk perjalanan jarak } \\
\text { jauh yang kompetitif } \\
\text { dengan pesawat terbang }\end{array}$ & $\begin{array}{l}\text { - Kereta api tidak dapat bersaing } \\
\text { dengan pesawat dari segi kecepatan } \\
\text { karena teknologi perkeretaapian di } \\
\text { Indonesia saat ini belum dapat } \\
\text { membuat kereta api cepat seperti di } \\
\text { Jepang maupun Cina. Sehingga } \\
\text { untuk bersaing dengan pesawat } \\
\text { kereta api harus unggul dari segi } \\
\text { pelayanan, fitur, dan fasilitas yaitu } \\
\text { dengan cara membuat kelas } \\
\text { eksekutif plus yang setara first class } \\
\text { pesawat. karena untuk penerbangan } \\
\text { domestik di Indonesia, belum ada } \\
\text { maskapai yang melayani } \\
\text { penerbangan first class. }\end{array}$ \\
\hline
\end{tabular}




\begin{tabular}{lll}
\hline Kereta yang ada belum & - & Fasilitas yang ada pada kereta saat ini \\
mempunyai fasilitas & hanya sekedar fasilitas standart dan \\
istimewa yang dapat & tidak bisa menarik pengguna \\
menarik pengguna & pesawat untuk beralih ke kereta api \\
pesawat beralih & Fasilitas kereta yang baru dapat \\
menggunakan kereta api & menunjang & kenyamanan \\
& (comfortable), hiburan \\
& (entertaintment), dan keramahan \\
& (hospitality). Ketiga kata kunci \\
& tersebut juga diterapkan sebagai \\
& konsep desain sehingga \\
& menghasilkan kereta yang dapat \\
& menarik perhatian pengguna \\
& pesawat. \\
&
\end{tabular}

Seni ITS, vol. 4, no. 2, Jan. 2016.

[2] W. Universitas Brawijaya. Program Pascasarjana, A.- Yuniarinto, and D.- Zain, "ANALISIS KUALITAS PELAYANAN DAN PENGARUHNYA TERHADAP KEPUASAN KONSUMEN (Studi Pada PT. Kereta Api (Persero) DAOP 8 Surabaya)," WACANA, J. Sos. dan Hum., vol. 13, no. 1, pp. 29-43, 2010.

[3] H. O. Yuwansa, "PENGAMBANGAN DESAIN LAYOUT, SEAT, DAN HANDEL KRDI MADIUN JAYA EKSPRESS AC DENGAN KONSEP FUTURISTIK," Surabaya, 2015.

[4] B. Tristiyono, "Desain Interior Kereta Api Kelas Eksekutif Generasi Terbaru Dengan Konsep Modular,” J. IDEA, 2009.

[5] K. Kottenhoff, "Passenger Train Design for Increased Competitiveness," Transp. Res. Rec. J. Transp. Res. Board, vol. 1623, pp. 144-151, Jan. 1998.

\section{DAFTAR PUSTAKA}

[1] A. Suprayitno, "Desain Carbody Eksterior dan Interior Tramway sebagai Ikon Angkutan Massal Cepat Kota Surabaya," J. Sains dan 